\title{
Marine Environmental Risk Assessment of Sungai Kilim, Langkawi, Malaysia: Heavy Metal Enrichment Factors in Sediments as Assessment Indexes
}

\author{
Jamil Tajam and Mohd Lias Kamal \\ Centre of Ocean Research, Conservation \& Advances (ORCA), Division of Research, Industrial Linkage, \\ Community Network \& Alumni, Universiti Teknologi MARA, 02600 Arau, Perlis, Malaysia \\ Correspondence should be addressed to Jamil Tajam; jamiltajam@perlis.uitm.edu.my
}

Received 4 December 2012; Revised 12 February 2013; Accepted 13 May 2013

Academic Editor: Heinrich Hühnerfuss

Copyright ( 2013 J. Tajam and M. L. Kamal. This is an open access article distributed under the Creative Commons Attribution License, which permits unrestricted use, distribution, and reproduction in any medium, provided the original work is properly cited.

Concentrations of $\mathrm{Cd}, \mathrm{Co}, \mathrm{Pb}$, and $\mathrm{Zn}$ in riverbed sediments from six sampling stations along the Sungai Kilim, Langkawi, Malaysia, were determined by using the Teflon Bomb Digestion. From this study, the concentrations of heavy metals in riverbed sediments were found ranging between 6.10 and $8.87 \mu \mathrm{g} / \mathrm{g}$ dry weight for Co, 0.03 and $0.45 \mu \mathrm{g} / \mathrm{g}$ dry weight for Cd, 59.8 and $74.9 \mu \mathrm{g} / \mathrm{g} \mathrm{dry}$ weight for $\mathrm{Zn}$, and 1.06 and $11.69 \mu \mathrm{g} / \mathrm{g}$ dry weight for Pb. From the observation, these areas were polluted by domestic waste, aquaculture, and tourism activities. For clarity, enrichment factor index was used to determine the level of sediment contamination in the study area. From this study, the average $\mathrm{EF}$ value is a bit high for $\mathrm{Cd}(2.15 \pm 1.17)$ followed by $\mathrm{Zn}(1.12 \pm 0.09), \mathrm{Pb}(0.44 \pm 0.32)$, and lastly, Co $(0.36 \pm 0.04)$. Based on the contamination categories, $\mathrm{Cd}$ was categorised as moderately enriched, while the rest of the metals studied were in deficient-to-minimally enriched by the anthropogenic sources.

\section{Introduction}

Heavy metals are one of the most poisonous and serious groups of pollutants due to their high toxicity, abundance, and ease of accumulation from various plants and animals. It has been accepted that heavy metals can exist in the environment deriving from a variety of natural and anthropogenic sources. The phenomena of erosion, acidification, and weathering processes have brought input of these metals into the environment in a natural way. According to Idris [1], the natural occurrence of heavy metals in aquatic environments and their movement through the hydrocycle in addition to the inputs from anthropogenic activities reflect their ubiquity and complexity. Meanwhile, human activities also contribute to the existence of these metals such as industrial processes, agricultural and aquaculture activities, domestic wastes, and emission from vehicles [2].

Nowadays, these anthropogenic heavy metals contribute to the uppermost pollution to the aquatic environment, especially in the sediment. Sediment plays a major role in determining the pollution pattern of marine ecosystem [3]. According to Singh et al. [4] and Mwamburi [5], the sediments can act as both carriers and sinks for contaminants, reflecting the history of pollution while also providing a record of catchment inputs into the aquatic ecosystem. On the other hand, sediment can play a significant role as a scavenger agent for heavy metals, and an adsorptive sink in marine environment $[6,7]$. Tsugonai and Yamada [8] further explained that aquatic sediment can act as scavengers of metals in the environment due to its several, sulfides, organic matter, iron and manganese oxides, and clays. Hence, the use of sediments is advantageous to assess human impacts on the marine environment.

For these reasons, the assessment of pollutants in the estuary system of Sungai Kilim, Langkawi, was carried out to perform the current sediment data assessment in order to assess its level of pollution in this area. Generally, Sungai Kilim is situated in the north-eastern region of Pulau Langkawi. The river is located at approximately $99^{\circ} 52^{\prime} 8.01^{\prime \prime} \mathrm{E}$ and $6^{\circ} 25^{\prime} 39.75^{\prime \prime}$ N. Sungai Kilim has become one of the popular sites to be visited for its attractive ecology and features. Due to its uniqueness, ecotourism benefits towards many locals and tourists [8]. The downstream of Sungai Kilim is characterized 


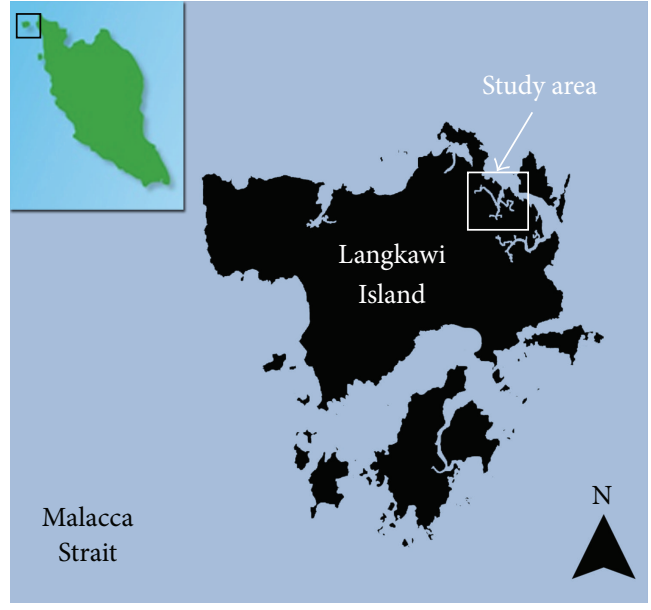

(a)

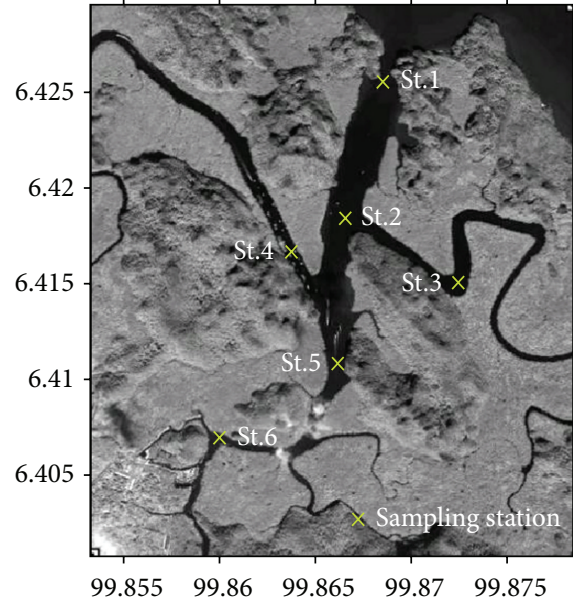

(b)

Figure 1: Sampling area.

by the high number of karst formations with high density of vegetative roots covering its surface. The middle stream is connected to two small rivers or tributaries. Beyond the upstream, urbanization conquered the banks where roads, restaurants, and tourist jetty are developed well for tourism activities.

Recently, quite a number of heavy metal assessment studies have been reported in this area. This assessment is particularly carried out in order to protect and conserve the environment of the Kilim River from further contamination by anthropogenic sources. Furthermore, the information gathered from this monitoring study may also provide an aid in the management of suitable policy for Langkawi Development Authority (LADA) to preserve the Sungai Kilim ecosystem as Kilim Karst Geoforest Park.

\section{Methodology}

2.1. Sample Collection and Preservation. Sample collection was conducted in December 2009 during the northeast monsoon season. Generally, Sungai Kilim, Langkawi (Figure 1) is very popular for a variety of ecotourism activities and due to this, major development has been done to improve the river's quality for providing the best services to tourists. These include eagle feeding activities (Station 3 ), floating restaurants, aquaculture (Station 4), yacht anchoring area (Station 4), and also boating services (Station 6). Therefore, six stations were established along the Sungai Kilim and marked using GPS (global positioning system) (Table 1). These locations were selected based on the fact that they might have been impacted by the nearby source of contamination. The distance between each station was approximately $1 \mathrm{~km}$. Riverbed sediment samples were collected using the Van Veen Grab, where afterwards, samples were placed in plastic bags which were previously immersed in 5\% nitric acid for two to three days to prevent sample contamination. The sediment samples were then preserved in the ice box at $4^{\circ} \mathrm{C}$ to maintain the original condition of the samples. At the laboratory, samples were dried in the oven at $105^{\circ} \mathrm{C}$ for 24 hours.
TABLE 1: The coordinates for each sampling station.

\begin{tabular}{lcc}
\hline Station & Latitude & Longitude \\
\hline 1 & $06^{\circ} 25^{\prime} 32.46^{\prime \prime} \mathrm{N}$ & $099^{\circ} 52^{\prime} 06.42^{\prime \prime} \mathrm{N}$ \\
2 & $06^{\circ} 25^{\prime} 05.14^{\prime \prime} \mathrm{N}$ & $099^{\circ} 51^{\prime} 57.91^{\prime \prime} \mathrm{N}$ \\
3 & $06^{\circ} 24^{\prime} 57.78^{\prime \prime} \mathrm{N}$ & $099^{\circ} 52^{\prime} 20.57^{\prime \prime} \mathrm{N}$ \\
4 & $06^{\circ} 25^{\prime} 00.96^{\prime \prime} \mathrm{N}$ & $099^{\circ} 51^{\prime} 47.58^{\prime \prime} \mathrm{N}$ \\
5 & $06^{\circ} 24^{\prime} 33.54^{\prime \prime} \mathrm{N}$ & $099^{\circ} 51^{\prime} 56.10^{\prime \prime} \mathrm{N}$ \\
6 & $06^{\circ} 24^{\prime} 24.66^{\prime \prime} \mathrm{N}$ & $099^{\circ} 51^{\prime} 34.92^{\prime \prime} \mathrm{N}$ \\
\hline
\end{tabular}

For heavy-metal analysis, it was ensured that the samples had been completely dried before grinding the samples with mortar and pestle and sieved under $63 \mu \mathrm{m}$ size. Precautions in preventing sample contamination were given priority. Samples were then stored in labelled plastic vials and kept in the drying cabinet until lab analysis.

2.2. Sample Digestion. In this study, the digestion and analytical procedures were adopted and applied from those of Kamaruzzaman [9], Jamil [10], and Trimm et al. [11] with little modifications. For this analysis, $0.05 \mathrm{~g}$ of the fine powder sediment $(<63 \mu \mathrm{m})$ was weighed and put into a Teflon vessel. After that, $1.5 \mathrm{~mL}$ of mixed acid $\left(2.5 \mathrm{HF}: 3 \mathrm{HNO}_{3}: 3 \mathrm{HCl}\right)$ was added into the Teflon vessels using a single channel pipette, 100-1000 microlitre $(\mu \mathrm{L})$ of the brand CappAero which was ISO 9001; 2000 certified. This digestion method is also known as the aqua regia + HF digestion method, which was also applied by Chen and Ma [12] and Deely and Fergusson [13]. Finally, the Teflon Bomb jackets were screwed tightly to prevent the appearance of silicate gel on their bodies, before placing the Teflon bombs into the oven for 6 hours at $160^{\circ} \mathrm{C}$. After 6 hours, they were cooled down under room temperature, where after that, $3.0 \mathrm{~mL}$ of acid solution composed of ethylenediaminetetraacetic acid (EDTA) and boric acid was added. The samples were then again put into the oven at $160^{\circ} \mathrm{C}$ for another 6 hours. The clear solution obtained was transferred into centrifuge tubes and meshed up to $10 \mathrm{~mL}$ with Mili-Q water. To verify the precision of the analytical 
TABLE 2: Five contaminant categories based on the EF value [25].

\begin{tabular}{lc}
\hline Enrichment factor $(\mathrm{EF})$ value & Contamination degree \\
\hline$<2$ & Deficiency to minimal enrichment \\
$2-5$ & Moderate enrichment \\
$5-20$ & Significant enrichment \\
$20-40$ & Very high enrichment \\
$>40$ & Extremely high enrichment \\
\hline
\end{tabular}

procedures, the sediment samples were analysed in three replicates for each sampling point and a sample blank. To confirm analytical accuracy, portions of certified reference materials (SRM1646a-estuarine sediments) from the National Institute of Standards and Technology (NIST) were analysed with each batch of samples. The concentrations of metals $(\mathrm{Cd}, \mathrm{Co}, \mathrm{Fe}, \mathrm{Pb}$, and $\mathrm{Zn})$ in the final digested solutions were then analysed using the Inductively Coupled Plasma Mass Spectrometer (Perkin Elmer. Elan 9000).

2.3. Ecological Risk Assessment. In this study, Fe is used as the normalized metal as it is an acceptable normalization element to be used in the calculation of enrichment factor since Fe distribution was not related to other heavy metals [13]. Fe usually has a relatively high natural concentration and is therefore not expected to be substantially enriched from anthropogenic sources in estuarine sediments [14]. These facts are in accordance with Daskalakis and O'Connor [15] who proposed that $\mathrm{Fe}$ is associated with fine solid surfaces, where its geochemistry is similar to that of many trace metals and its natural sediment concentration tends to be uniform. Moreover, a wide range of studies have used $\mathrm{Fe}$ and $\mathrm{Al}$ normalizations as an alternative to grain-size normalization $[16,17]$. The enrichment factors (EFs) for each metal were calculated based on the formula following [18-20]:

$$
\mathrm{EF}=\frac{\left(C_{s} / C_{\mathrm{Fe}}\right)_{\text {sample }}}{\left(C_{s} / C_{\mathrm{Fe}}\right)_{\text {crust }}} .
$$

Meanwhile, the values for the earth's crustal elements were taken from Carmichael [21], Bodek et al. [22], and Ronov and Yaroshevsky [23], as published by Lide [24]. The resulting values were then referred to the contaminant categories proposed by Sutherland [25] to reveal and acknowledge the enrichment degree of the heavy metals as illustrated by Table 2 .

\section{Result and Discussion}

For method validation, certified reference material (SRM1646a) was determined as a precision check. The percentage of recoveries ( $n=5$ for each metal) for certified and measured concentration of those metals was satisfactory, with the recoveries being $81.67-102.24 \%$. Table 3 shows the recovery test results for SRM (1646a) analysis.

From this study, the heavy metal contents of the sediment were analysed, and the results were depicted in Table 4 . The trend of mean concentration of heavy metals in Sungai Kilim
TABLE 3: Recovery test results (concentration for Fe is in percentage (\%), while other metals are in $\mu \mathrm{g} / \mathrm{g}$ dry weight).

\begin{tabular}{lccc}
\hline Heavy metals & Measured SRM & Certified value & Recovery (\%) \\
\hline Iron, Fe & $2.053 \pm 0.115 \%$ & $2.008 \pm 0.039 \%$ & 102.24 \\
Cadmium, Cd & $0.127 \pm 0.011$ & $0.148 \pm 0.007$ & 85.81 \\
Cobalt, Co & $4.726 \pm 0.028$ & 5.000 & 94.52 \\
Lead, $\mathrm{Pb}$ & $9.552 \pm 0.473$ & $11.7 \pm 1.2$ & 81.67 \\
Zinc, $\mathrm{Zn}$ & $45.389 \pm 0.698$ & $48.9 \pm 1.60$ & 92.82 \\
\hline
\end{tabular}

was $\mathrm{Fe}>\mathrm{Zn}>\mathrm{Co}>\mathrm{Pb}>\mathrm{Cd}$. According to Table 4, the concentration of Fe along the stations increased toward the upstream area, with the average value of $4.803 \pm 0.422 \%$. The maximum and minimum concentration of $\mathrm{Fe}$ were obtained from St. 5 and St. 1 with the values $5.230 \%$ and $4.086 \%$ respectively. Furthermore, the highest concentration of $\mathrm{Zn}$ was found at St. 6 with a value of $74.923 \mu \mathrm{g} / \mathrm{g}$ dry weight, whereas the lowest concentration was found at St.1 with a concentration of $59.81 \mu \mathrm{g} / \mathrm{g}$ dry weight. As for Zn, $66.817 \pm 4.856 \mu \mathrm{g} / \mathrm{g}$ dry weight of $\mathrm{Zn}$ has been found distributed along Sungai Kilim. In the meantime, $\mathrm{Co}$ and $\mathrm{Pb}$ displayed the highest value at St.2 (8.872 $\mu \mathrm{g} / \mathrm{g}$ dry weight) and St.4 (11.69 $\mu \mathrm{g} / \mathrm{g}$ dry weight), correspondingly. Lastly, $\mathrm{Cd}$ was distributed unevenly along the river with the range value of $0.026-0.452 \mu \mathrm{g} / \mathrm{g}$ dry weight. According to the conducted statistical analysis of 2way ANOVA, there was a significant difference between the sampling stations $(P<0.05)$.

According to Rickard and Niagru [26] and Muller [27], the high concentration of heavy metals is usually not only influenced by the chemical processes but also by anthropogenic activities. Hence, these anthropogenic activities carried along the river plus the increase of development in that area are seen to have impacted the river as the domestic sewage, oil spill, and aquaculture, and many more are considered to be common sights. On average, Fe concentration in Sungai Kilim was lower compared to the earth's crust value (5.635\%). It was found that Fe was more concentrated at St.5 rather than the downstream, which could be possibly caused by the weathering process of sedimentary rocks that enter the river. Williamson [28] had stated that typical levels for $\mathrm{Fe}$ in sedimentary rocks are given as limestone $0.33 \%$, sandstone $0.98 \%$, shale $4.7 \%$, and banded iron formation $28 \%$. The distribution of Fe was rather uniform along the river, decreasing towards downstream. This trend suggests that only a small amount of Fe has been drifting downstream.

From the observation, the highest $\mathrm{Zn}$ concentration value was discovered at St.6 (upstream) and constantly decreasing towards the downstream area. This might be due to the bat waste from the bat cave at the upstream area. According to Miko et al. [29], bat droppings contain a relatively high content of $\mathrm{Zn}$; thus, this could justify the source of $\mathrm{Zn}$ in this area. In addition, Davis et al. [30] showed that urban runoff might be slightly smaller. This is in agreement with Roney et al. [31] who found that $\mathrm{Zn}$ and its compounds are present in the Earth's crust and in most rocks, certain minerals, and some carbonate sediments, and, as a result of weathering effects towards these materials, soluble compounds of zinc are formed and may be released to water [32]. On the other hand, 
TABLE 4: Heavy metal in each station (concentration for Fe is depicted in percentage (\%), while other metals are in $\mu \mathrm{g} / \mathrm{g}$ dry weight).

\begin{tabular}{lcccccccc}
\hline Heavy metals & St.1 & St.2 & St.3 & St.4 & St.5 & St.6 & Average & One-way ANOVA \\
\hline $\mathrm{Cd}$ & 0.288 & 0.388 & $\mathbf{0 . 4 5 2}$ & 0.026 & 0.201 & 0.294 & $0.275 \pm 0.137$ & $P<0.05^{*}$ \\
$\mathrm{Co}$ & 7.989 & $\mathbf{8 . 8 7 2}$ & 7.686 & 6.104 & 7.761 & 7.756 & $7.695 \pm 0.818$ & $P<0.05^{*}$ \\
$\mathrm{Fe}$ & 4.086 & 4.939 & 4.939 & 4.402 & $\mathbf{5 . 2 3 0}$ & 5.222 & $4.803 \pm 0.422$ & $P<0.05^{*}$ \\
$\mathrm{~Pb}$ & 6.508 & 1.057 & 1.844 & $\mathbf{1 1 . 6 9}$ & 5.571 & 5.079 & $5.292 \pm 3.473$ & $P<0.05^{*}$ \\
$\mathrm{Zn}$ & 59.81 & 66.918 & 62.245 & 68.308 & 68.697 & $\mathbf{7 4 . 9 2 3}$ & $66.817 \pm 4.856$ & $P<0.05^{*}$ \\
\hline
\end{tabular}

*There are significant differences between the sampling stations.

TABLE 5: The comparison of heavy metal concentrations in the present study with other heavy metal studies throughout Malaysia.

\begin{tabular}{lccccccc}
\hline No. & Area & $\mathrm{Cd}$ & $\mathrm{Co}$ & $\mathrm{Fe}$ & $\mathrm{Pb}$ & $\mathrm{Zn}$ & References \\
\hline$(1)$ & Sungai Kilim, Langkawi & $0.27 \pm 0.14$ & $7.69 \pm 0.82$ & $4.80 \pm 0.42$ & $5.29 \pm 3.47$ & $66.82 \pm 4.86$ & Present study \\
$(2)$ & Terengganu River & $0.9 \pm 1.7$ & $15.1 \pm 7.4$ & $6.3 \pm 1.3$ & $44.1 \pm 14.4$ & $65.6 \pm 34.8$ & Jamil [10] \\
$(3)$ & Kemaman estuary & - & 16.00 & - & - & - & Kamaruzzaman and Ong [40] \\
$(4)$ & Sungai Kelantan & $1.82 \pm 0.02$ & - & 3.860 & $20.82 \pm 0.28$ & $18.67 \pm 0.56$ & Ahmad et al. [41] \\
$(5)$ & Langkawi coastal water & - & - & - & $41.87 \pm 7.3$ & - & Kamaruzzaman et al. [42] \\
$(6)$ & Sungai Semenyih & - & $20.95 \pm 12.97$ & - & $44.71 \pm 22.34$ & $62 \pm 36.34$ & Muhammad et al. [43] \\
$(7)$ & Kuala Perlis & - & - & - & 25.77 & 55.73 & Yap and Pang [44] \\
$(8)$ & Kuala Kedah jetty & - & - & - & 26.81 & 53.21 & Yap and Pang [44] \\
$(9)$ & Kuala Muda & - & - & - & 31.92 & 33.6 & Yap and Pang [44] \\
$(10)$ & Kuala Juru jetty & - & - & - & 30.20 & 317.39 & Yap and Pang [44] \\
$(11)$ & Juru industrial drainage & - & - & - & 65.32 & 484.14 & Yap and Pang [44] \\
$(12)$ & Earth bulk continental crust & 0.15 & 25 & 5.63 & 14 & 70 & Lide [24] \\
\hline
\end{tabular}

Monaci and Bargagli [33] have also found that the possible source of $\mathrm{Zn}$ may also be from motor oil, grease, phosphate fertilizers, sewage sludge, transmission fluid, undercoating, asphalt, and concrete.

Meanwhile, the average concentration of both Co and $\mathrm{Pb}$ in this study area was discovered to be slightly lower than the earth's crust value. Faroon et al. [34] stated that the primary anthropogenic sources of Co lie in phosphate fertilizers, which, in this study, could be due to bat waste and aquaculture activities. Naylor et al. [35] have reported that fish pellets also contain some cobalt elements. A very high concentration of $\mathrm{Pb}$ at $\mathrm{St} .4$ revealed that the surroundings were heavily contaminated with leaded petrol stemmed from outboard boat engines from boating activities and places of anchored yacht that were very concentrated in that particular area compared to the other stations. The contamination of $\mathrm{Pb}$ has been the major attention of many researchers such as Lee et al. [36], Alloway [37], and Monaci and Bargagli [33], where they have confirmed that leaded fuel, automobile or motor exhaust, lubricating oil, and grease are the possible major sources of $\mathrm{Pb}$.

Lastly, the Cd concentration for all sampling stations was dramatically higher than that of the earth's crust value, except for St.4. From the observation, the highest concentration indicated that the main source of heavy metal enrichment came from anthropogenic elements deposited directly or indirectly by human activities such as boat cruising along the study area. According to Miko et al. [29], oil combustion from the boating activities was the main factor that influenced the increase of Cd. On the other hand, Dong et al. [38] stated that human activities including discharges of municipal wastewater, agriculture, mining, fossil fuels, and industrial wastewater are a major source of Cd contamination in the marine environment especially in estuaries. Cd however has a very low solubility in aqueous solution. It is readily adsorbed to suspended solids, where, after a series of natural processes, Cd particles will finally sink and accumulate in sediments [39].

The comparison of heavy metal compositions made between the study area and other places in Malaysia is available in Table 5. The table shows the value of heavy metal concentrations reported by previous researchers, namely Kamaruzzaman and Ong [40], Jamil [10], Ahmad et al. [41], Kamaruzzaman et al. [42], Muhammad et al. [43] and Yap and Pang [44]. Based on Table 5, Zn concentration in the present study area was found to be relatively lower compared to the Juru area and earth bulk continental crust but higher compared to other places. Meanwhile, the other metals obtained seemed to have lower concentrations with respect to the other places in Malaysia.

For a better estimation of anthropogenic input, an enrichment factor (EF) was calculated for each metal by dividing its ration to the normalizing element by the same ration found in the chosen baseline. Generally, throughout this study, it was found that Fe distribution was rather uniform along the river, which indicates a good stability of the metal in the river as a whole. The good stability of Fe along the river signifies and ascertains its capability to be adopted as the most suitable normalizing element for this study compared to other metals, particularly in this study area. According to Figure 2, 


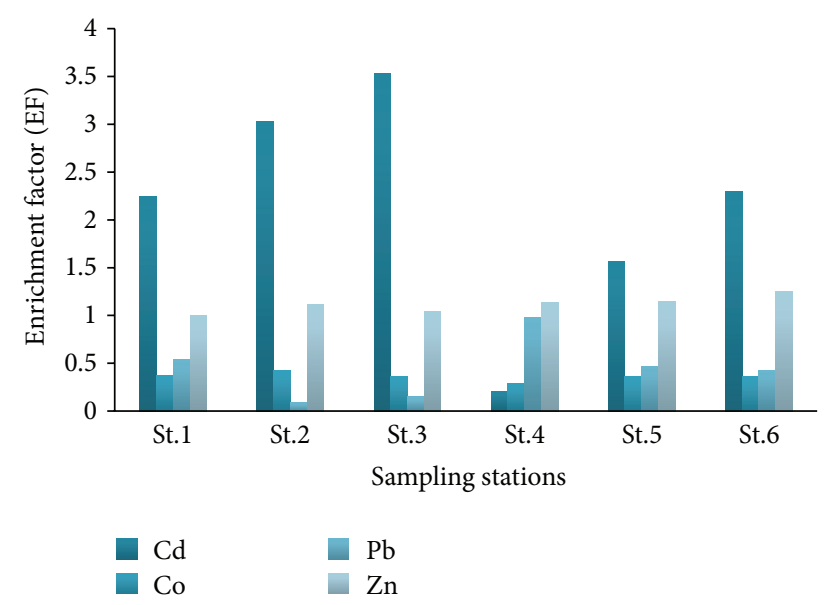

FIGURE 2: Enrichment factors for each heavy metal in the study area.

the EF value of Cd $(2.15 \pm 1.17)$ for all stations was higher than 2.0 except for St. 4 and St.5. This means that a significant portion of heavy metals was provided by anthropogenic sources mainly from the oil combustion from boating activities. However, $\mathrm{Co}(0.36 \pm 0.04), \mathrm{Pb}(0.44 \pm 0.32)$, and $\mathrm{Zn}(1.12 \pm 0.09)$ obtained minimal enrichment $(<2.0)$ for all stations. The data obtained will provide scientific evidence and may be referred to as the baseline data for a better understanding of our estuary ecosystem. In Malaysia, especially in Langkawi area, studies regarding heavy-metal pollution are currently quite limited. Therefore, continuous monitoring of heavy-metal pollution in this environment is definitely indispensable.

\section{Conclusion}

From this study, the overall trend of mean concentration of heavy metals in Sungai Kilim can be concluded by the following order: $\mathrm{Fe}>\mathrm{Zn}>\mathrm{Co}>\mathrm{Pb}>\mathrm{Cd}$. However, the distribution of $\mathrm{Cd}$ in the sediment was found to be higher than that of the earth's crust value, while other metals (Co, Fe, $\mathrm{Pb}$, and $\mathrm{Zn}$ ) were found to be of lower values. To clarify and validate how serious the contamination level of each metal to the river is, the enrichment factor (EF) was applied. According to this approach, the river was moderately enriched by $\mathrm{Cd}$. The higher concentrations of $\mathrm{Cd}$ in the study area were estimated to have originated from the oil combustion of boating activities along the study area.

\section{Acknowledgments}

This research was conducted under the funding of University Teknologi MARA (UiTM), through the Research Excellence Fund. The authors wish to express their gratitude to the Oceanography Laboratory team members for their invaluable assistance and hospitality throughout the sampling period.

\section{References}

[1] A. M. Idris, "Combining multivariate analysis and geochemical approaches for assessing heavy metal level in sediments from
Sudanese harbors along the Red Sea coast," Microchemical Journal, vol. 90, no. 2, pp. 159-163, 2008.

[2] A. Demirak, F. Yilmaz, A. Levent Tuna, and N. Ozdemir, "Heavy metals in water, sediment and tissues of Leuciscus cephalus from a stream in southwestern Turkey," Chemosphere, vol. 63, no. 9, pp. 1451-1458, 2006.

[3] J. M. Casas, H. Rosas, M. Solé, and C. Lao, "Heavy metals and metalloids in sediments from the Llobregat basin, Spain," Environmental Geology, vol. 44, no. 3, pp. 325-332, 2003.

[4] K. P. Singh, D. Mohan, V. K. Singh, and A. Malik, "Studies on distribution and fractionation of heavy metals in Gomti river sediments-a tributary of the Ganges, India," Journal of Hydrology, vol. 312, no. 1-4, pp. 14-27, 2005.

[5] J. Mwamburi, "Variations in trace elements in bottom sediments of major rivers in Lake Victoria's basin, Kenya," Lakes and Reservoirs: Research and Management, vol. 8, no. 1, pp. 5-13, 2003.

[6] A. Tessier and P. G. C. Campbell, "Partitioning of trace metals in sediments: relationships with bioavailability," Hydrobiologia, vol. 149, no. 1, pp. 43-52, 1987.

[7] N. W. Chan, "Protecting and conserving our natural heritage: potentials, threats and challenges of Langkawi Geopark," in Proceedings of the International Conference World Civic Forum, Seoul, South Korea, May 2009.

[8] S. Tsugonai and M. Yamada, "226Ra in Bering sea sediment and its application as a geochronometer," Geochemical Journal, vol. 13, pp. 231-238, 1980.

[9] B. Y. Kamaruzzaman, Geochemistry or the marine sediments. Its paleoceanographic significance [Ph.D. thesis], Hokkaido University, 1999.

[10] T. Jamil, Physicochemical and sediment characteristics of the bottom sediment of Terengganu River, Terengganu Malaysia [M.S. thesis], Kolej Universiti Sains dan Teknologi Malaysia, 2006.

[11] D. L. Trimm, H. H. Beiro, and S. J. Parker, “Comparison of digestion techniques in analyses for total metals in marine sediments," Bulletin of Environmental Contamination and Toxicology, vol. 60, no. 3, pp. 425-432, 1998.

[12] M. Chen and L. Q. Ma, "Comparison of three aqua regia digestion methods for twenty Florida soils," Soil Science Society of America Journal, vol. 65, no. 2, pp. 491-499, 2001.

[13] J. M. Deely and J. E. Fergusson, "Heavy metal and organic matter concentrations and distributions in dated sediments of a small estuary adjacent to a small urban area," The Science of the Total Environment, vol. 153, no. 1-2, pp. 97-111, 1994.

[14] L. F. Niencheski, H. L. Windom, and R. Smith, "Distribution of particulate trace metal in Patos Lagoon estuary (Brazil)," Marine Pollution Bulletin, vol. 28, no. 2, pp. 96-102, 1994.

[15] K. D. Daskalakis and T. P. O'Connor, "Normalization and elemental sediment contamination in the coastal United States," Environmental Science and Technology, vol. 29, no. 2, pp. 470477, 1995.

[16] V. T. Breslin and S. A. Sañudo-Wilhelmy, "High spatial resolution sampling of metals in the sediment and water column in Port Jefferson Harbor, New York," Estuaries, vol. 22, no. 3, pp. 669-680, 1999.

[17] H. L. Windom, S. J. Schropp, F. D. Calder et al., "Natural trace metal concentrations in estuarine and coastal marine sediments of the Southeastern United States," Environmental Science and Technology, vol. 23, no. 3, pp. 314-320, 1989.

[18] S. Covelli and G. Fontolan, "Application of a normalization procedure in determining regional geochemical baselines," Environmental Geology, vol. 30, no. 1-2, pp. 34-45, 1997. 
[19] V. Simeonov, D. L. Massart, G. Andreev, and S. Tsakovski, "Assessment of metal pollution based on multivariate statistical modeling of "hot spot" sediments from the Black Sea," Chemosphere, vol. 41, no. 9, pp. 1411-1417, 2000.

[20] L. Zhang, X. Ye, H. Feng et al., "Heavy metal contamination in western Xiamen Bay sediments and its vicinity, China," Marine Pollution Bulletin, vol. 54, no. 7, pp. 974-982, 2007.

[21] R. S. Carmichael, CRC Practical Handbook of Physical Properties of Rocks and Minerals, CRC Press, Boca Raton, Fla, USA, 1989.

[22] I. Bodek, W. J. Lyman, W. F. Reehl, and D. H. Rosenblatt, Environmental Inorganic Chemistry, Pergamon Press, New York, NY, USA, 1988.

[23] A. B. Ronov and A. A. Yaroshevsky, "Earth's crust geochemistry," in Encyclopedia of Geochemistry and Environmental Sciences, R. W. Fairbridge, Ed., Van Nostrand, New York, NY, USA, 1969.

[24] D. R. Lide, CRC Handbook of Chemistry and Physics, CRC Press, Boca Raton, Fla, USA, 85th edition, 2005.

[25] R. A. Sutherland, "Bed sediment-associated trace metals in an urban stream, Oahu, Hawaii," Environmental Geology, vol. 39, no. 6, pp. 611-627, 2000.

[26] D. T. Rickard and J. O. Niagru, "Aqueous environmental chemistry of lead," in The Biochemistry of Lead in the Environment: Part A. Ecological Cycles, pp. 219-284, Elsevier, Amsterdam, The Netherlands, 1978.

[27] F. L. L. Muller, "Colloid/solution partitioning of metal-selective organic ligands, and its relevance to $\mathrm{Cu}, \mathrm{Pb}$ and $\mathrm{Cd}$ cycling in the firth of Clyde," Estuarine, Coastal and Shelf Science, vol. 46, no. 3, pp. 419-437, 1998.

[28] M. A. Williamson, "Iron," in Encyclopedia of Geochemistry, C. P. Marshall and R. W. Fairbridge, Eds., pp. 348-353, Kluwer Academic, Dordrecht, Germany, 1999.

[29] S. Miko, M. Kuhta, and S. Kapelj, "Environmental baseline geochemistry of sediments and percolating waters in the Modric Cave, Croatia," Acta Carsologica, vol. 31, no. 1, pp. 135-149, 2002.

[30] A. P. Davis, M. Shokouhian, and S. Ni, "Loading estimates of lead, copper, cadmium, and zinc in urban runoff from specific sources," Chemosphere, vol. 44, no. 5, pp. 997-1009, 2001.

[31] N. Roney, V. Cassandra, M. Williams, M. Osier, and S. J. Paikoff, Toxicological Profile for Zinc, U.S. Department Of Health And Human Services Public Health Service Agency for Toxic Substances and Disease Registry, 2005.

[32] NAS, "Inorganic solutes," in Drinking Water and Health, vol. 1, pp. 205-229, National Academy of Sciences; National Academy Press, Washington, DC, USA, 1977.

[33] F. Monaci and R. Bargagli, "Barium and other trace metals as indicators of vehicle emissions," Water, Air, and Soil Pollution, vol. 100, no. 1-2, pp. 89-98, 1997.

[34] O. M. Faroon, H. Abadin, S. Keith et al., Toxicological Profile for Cobalt, U.S. Department of Health and Human Services Public Health Service Agency for Toxic Substances and Disease Registry, 2004.

[35] S. J. Naylor, R. D. Moccia, and G. M. Durant, "The chemical composition of settleable solid fish waste (Manure) from commercial rainbow trout farms in Ontario, Canada," North American Journal of Aquaculture, vol. 61, no. 1, pp. 21-26, 1999.

[36] D. S. Lee, J. A. Garland, and A. A. Fox, "Atmospheric concentrations of trace elements in urban areas of the United Kingdom," Atmospheric Environment, vol. 28, no. 16, pp. 2691-2713, 1994.

[37] B. J. Alloway, Heavy Metals in Soils, Blackie Academic and Professional, Glasgow, UK, 2nd edition, 1995.
[38] C. D. Dong, C. F. Chen, M. S. Ko, and C. W. Chen, "Enrichment, accumulation and ecological risk evaluation of cadmium in the surface sediments of Jen-Gen River Estuary, Taiwan," International Journal of Chemical Engineering and Applications, vol. 3, no. 6, pp. 370-373, 2012.

[39] C. W. Chen, C. F. Chen, and C. D. Dong, "Contamination and potential ecological risk of mercury in sediments of Kaohsiung River mouth, Taiwan," International Journal of Environmental Science and Development, vol. 3, pp. 66-71, 2012.

[40] Y. Kamaruzzaman and M. C. Ong, "Geochemical proxy of some chemical elements in sediments of kemaman river Estuary, Terengganu, Malaysia," Sains Malaysiana, vol. 38, no. 5, pp. 631636, 2009.

[41] A. K. Ahmad, I. Mushrifah, and M. Shuhaimi-Othman, "Water quality and heavy metal concentrations in sediment of Sungai Kelantan, Kelantan, Malaysia: a baseline study,' Sains Malaysiana, vol. 38, no. 4, pp. 435-442, 2009.

[42] B. Y. Kamaruzzaman, N. T. Shuhada, B. Akbar et al., "Spatial concentrations of lead and copper in bottom sediments of Langkawi Coastal Area, Malaysia," Research Journal of Environmental Sciences, vol. 5, pp. 179-186, 2011.

[43] B. G. Muhammad, N. A. S. Wan, and I. Mohd, "Sebaran logam berat dalam lembangan sungai semenyih," in Proceedings of the Regional Symposium on Environment and Natural Resources, vol. 1, pp. 595-602, Kuala Lumpur, Malaysia, April 2002.

[44] C. K. Yap and B. H. Pang, "Assessment of $\mathrm{Cu}, \mathrm{Pb}$, and $\mathrm{Zn}$ contamination in sediment of north western Peninsular Malaysia by using sediment quality values and different geochemical indices," Environmental Monitoring and Assessment, vol. 183, no. 1-4, pp. 23-39, 2011. 

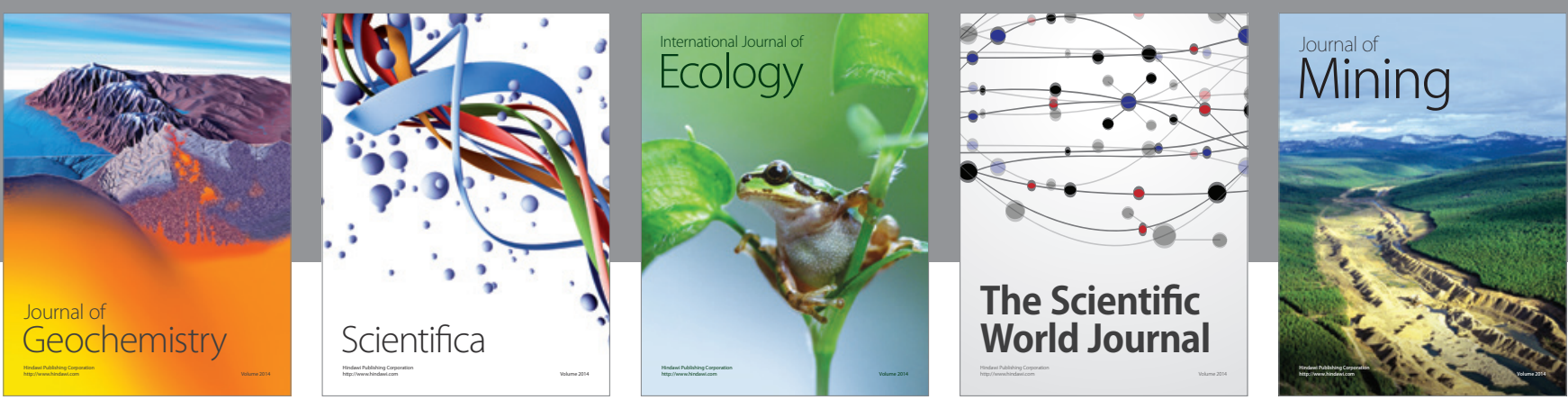

The Scientific World Journal
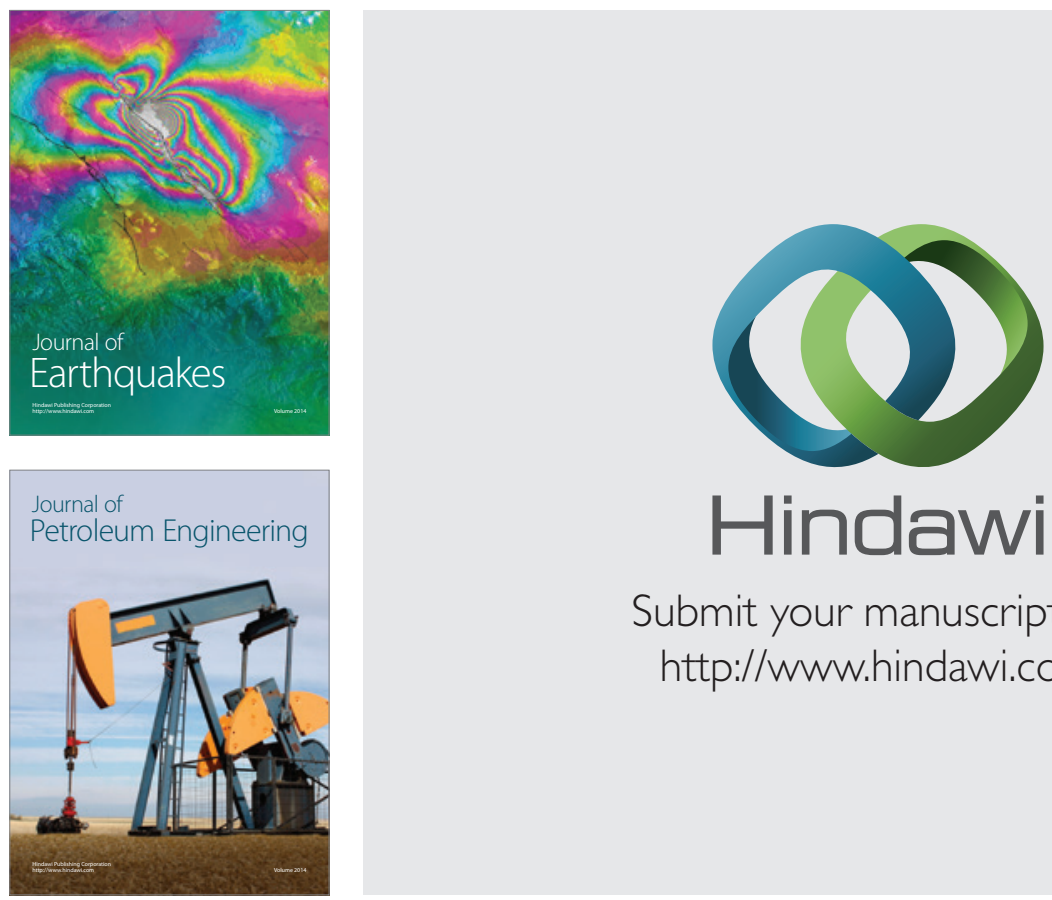

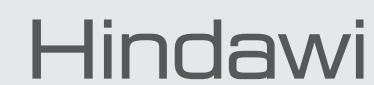

Submit your manuscripts at

http://www.hindawi.com
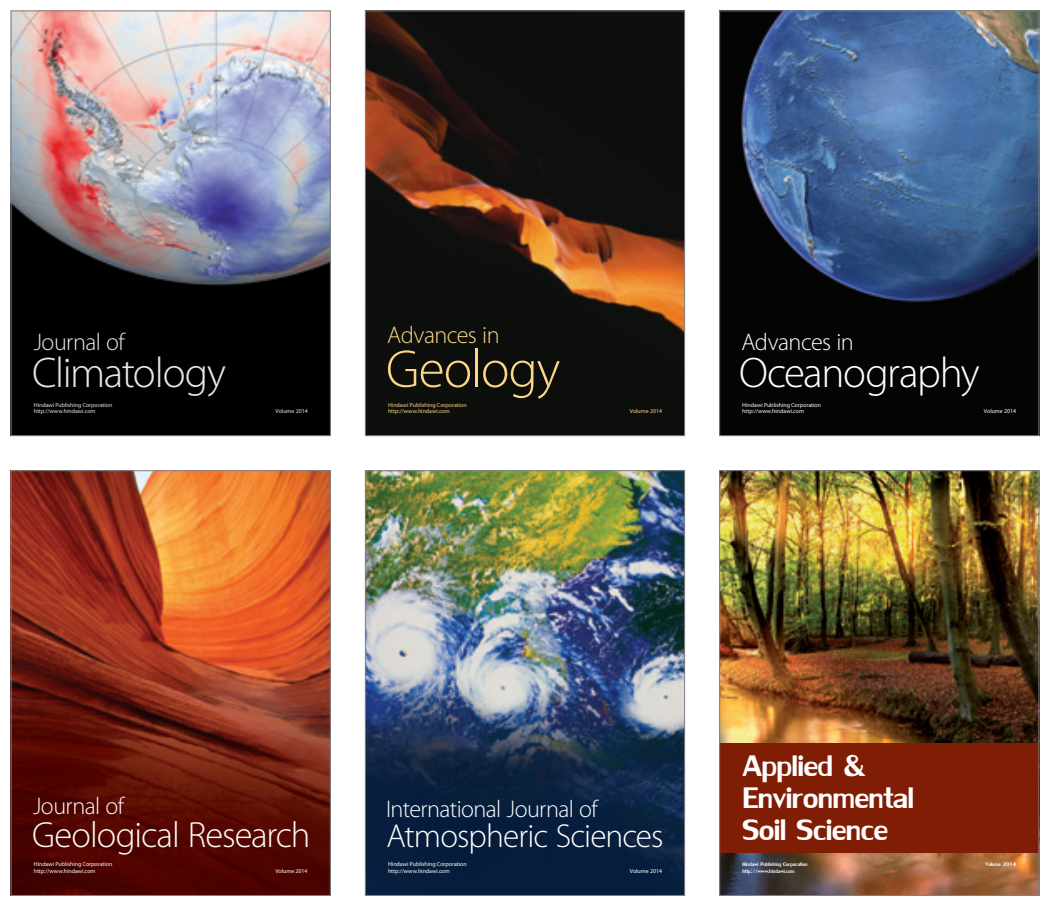
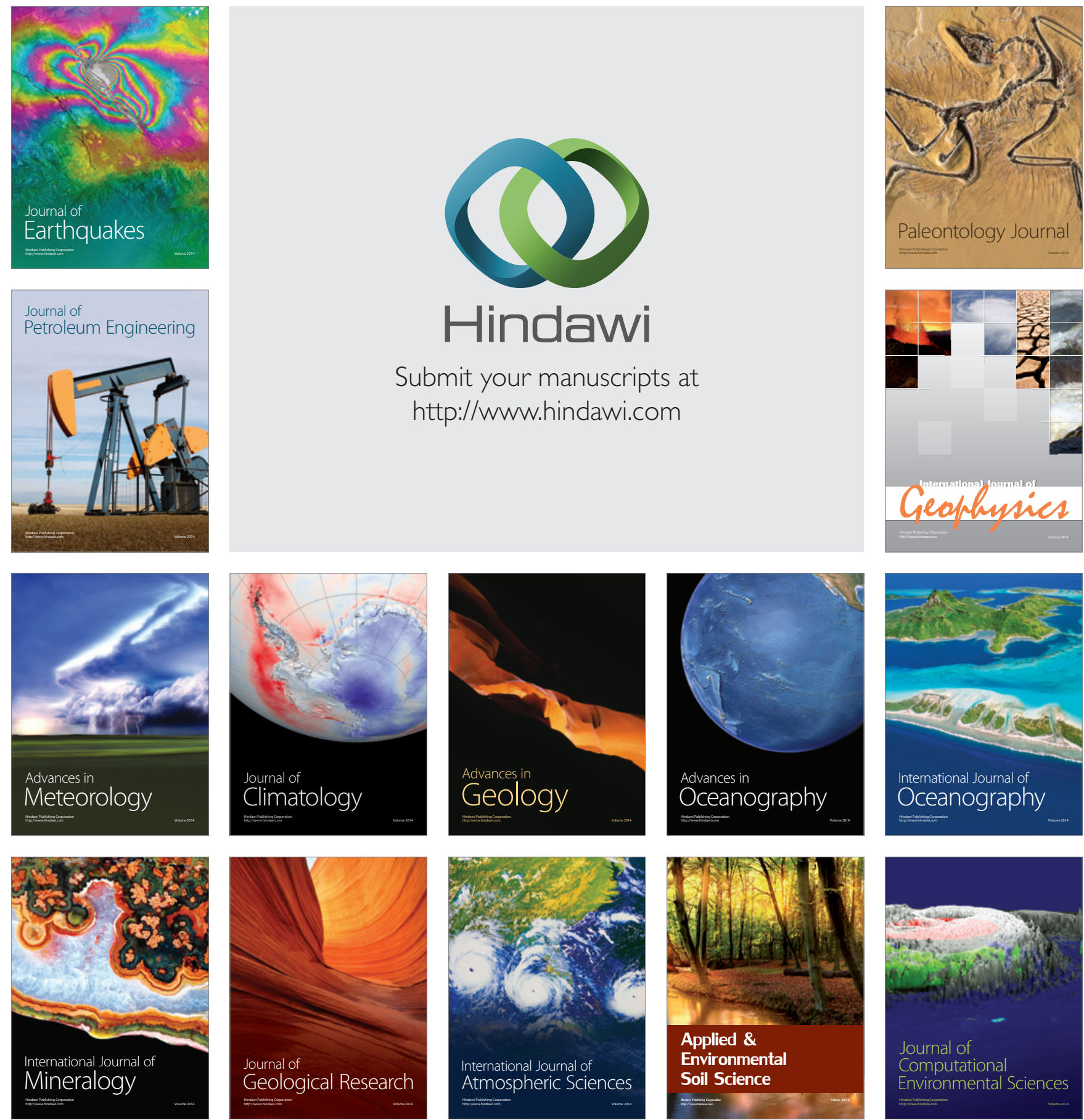